\title{
A produção familiar de alimentos no contexto da tradição e da resistência
}

\author{
The family food production \\ in the context of tradition and resistance
}

Erica Karnopp

Universidade de Santa Cruz do Sul - UNISC - Santa Cruz do Sul - Rio Grande do Sul - Brasil

\section{Virginia Elisabeta Etges}

Universidade de Santa Cruz do Sul - UNISC - Santa Cruz do Sul - Rio Grande do Sul - Brasil

\section{Ana Claudia Guske}

Universidade de Santa Cruz do Sul - UNISC - Santa Cruz do Sul - Rio Grande do Sul - Brasil

\begin{abstract}
Resumo: A globalização dos mercados e a consequente integração da economia modificam estruturas sociais em diferentes pontos do planeta, dentre elas as da produção de alimentos. Este artigo resulta de uma investigação que objetivou analisar de que modo a tradição alimentar, enquanto prática relacionada ao saber-fazer, transmitida através de gerações, manifesta-se nas agroindústrias familiares, produtoras de alimentos, localizadas na microrregião norte da região do Conselho Regional de Desenvolvimento - Corede, do Vale do Rio Pardo. No contexto desta pesquisa a tradição se apresenta como resistência. Ela se manifesta como um fator de reflexão frente às transformações provocadas pelos mecanismos globais de dominação. As famílias produtoras de alimentos tradicionais, através das agroindústrias familiares na Microrregião Norte do Corede do Vale do Rio Pardo, manifestam-se simbolicamente contra a homogeneização alimentar, apresentando resistência à imposição de um padrão industrial de alimentação e podem ser entendidas como uma reação ao domínio atual dos mercados.
\end{abstract}

Palavras-chave: Agricultura familiar. Tradição. Resistência.

Abstract: The globalization of markets and the consequent integration of the economy modify social structures in different parts of the planet, among them those of food production. This article is the result of an investigation aimed at analyzing how the food tradition, as a practice related to know-how, passed down through generations, is manifested in the family food-producing agroindustries located in the northern microregion of the region of the Regional Council of Development - Corede, of the Pardo River Valley. In the context of this research tradition is presented as resistance. It manifests itself as a reflection factor in the face of the transformations provoked by the global mechanisms of domination. Traditional food-producing households, through the family agro-industries in the Northern Microp region of the Cordo do Rio Pardo Valley, manifest themselves symbolically against food homogenization, presenting resistance to the imposition of an industrial food standard and can be understood as a reaction to the domain Markets.

Keywords: Family agriculture. Tradition. Resistance. 


\section{Introdução}

A globalização dos mercados e a consequente integração da economia modificam estruturas sociais em diferentes pontos do planeta. A vulnerabilidade social é a consequência mais imediata desse processo.

Em decorrência dos processos de reestruturação capitalista e do aumento da vulnerabilidade social e econômica no meio rural, apresenta-se crescente a tendência de diversificação produtiva na agricultura familiar. Nesse sentido, várias estratégias de desenvolvimento, determinadas por dinâmicas endógenas, têm sido identificadas, merecendo destaque as agroindústrias familiares.

Este artigo resulta de uma investigação que objetivou analisar de que modo a tradição alimentar, enquanto prática relacionada ao saber-fazer, transmitida através de gerações, manifesta-se nas agroindústrias familiares, produtoras de alimentos, localizadas na microrregião norte da região do Conselho Regional de Desenvolvimento - Corede, do Vale do Rio Pardo, composto pelos municípios de Arroio do Tigre, Estrela Velha, Ibarama, Lagoa Bonita do Sul, Passa Sete, Segredo, Sobradinho e Tunas.

Os estabelecimentos pesquisados foram as agroindústrias familiares formalizadas entre 2000 e 2015, para fins de delimitação temporal foi considerado 0 ano de formalização da primeira agroindústria até 0 ano anterior a coleta de dados. Cabe ressaltar que, para fins desta pesquisa, as agroindústrias familiares de alimentos formalizadas até 2015 na Microrregião Norte do Corede do Vale do Rio Pardo serão tratadas apenas como "agroindústrias familiares".

As agroindústrias familiares formalizadas são compreendidas como aquelas geridas pelo grupo familiar que cumprem as obrigações legais exigidas pelos órgãos competentes. Quando a agroindústria familiar possui laudos de licença sanitária, ambiental e da potabilidade da água, ela se torna legalizada, estando apta a receber o Selo Sabor Gaúcho. De acordo com os propósitos desta investigação, as agroindústrias familiares que atendem aos requisitos formais, comercializando aos produtos alimentares conforme as determinações legais, são tratadas como agroindústrias familiares formalizadas.

Atualmente, o Corede do Vale do Rio Pardo é um dos 28 Coredes do Estado do Rio Grande do Sul e conta com 23 municípios (FEE, 2015), fazendo parte de uma estratégia de organização regional do Brasil que visa ao desenvolvimento das regiões. Caracteriza-se como uma "entidade de direito privado, organizada sob a forma de associação civil, sem fins lucrativos e com prazo de duração indeterminado" (SILVEIRA; CAMPOS, 2012, p. 210).

A localização do Corede do Vale do Rio Pardo estende-se desde a Encosta do Planalto Meridional, parte da Depressão Central, até a Campanha, abrangendo a área central do Estado do Rio Grade do Sul, conforme mostra a Figura 1.

Nos municípios da Microrregião Norte do Corede do Vale do Rio Pardo a maior parte da população encontra-se na área rural. Somente no município de Sobradinho o percentual populacional se comporta de modo diferenciado, neste município a maioria da população se encontra na área urbana. Essa disposição no recorte espacial da pesquisa destaca a importância que o rural possui perante as questões inerentes ao desenvolvimento.

A Microrregião Norte do Corede do Vale do Rio Pardo, objeto desta pesquisa, caracteriza-se como "uma área de predomínio da pequena propriedade, com uma população constituída por descendentes de alemães, italianos e luso-brasileiros, e com sérios problemas no tocante a alternativas econômicas que agreguem valor à produção do minifúndio" (KLARMANN, 1999, p. 147).

Nessa região, existem aproximadamente 51 agroindústrias familiares de alimentos ${ }^{1}$, sendo que $25 \%$ delas estão formalizadas ${ }^{2}$. A presença de um número relevante de agroindústrias de cunho familiar que produzem alimentos se mostra significativo no contexto em que estão inseridas.

\footnotetext{
1 Informação fornecida pelo Arranjo Produtivo Local de Agroindústria e Alimentos da Agricultura Familiar do Vale do Rio Pardo em julho de 2015.

2 Informação fornecida pelos escritórios da Emater dos municípios pesquisados em fevereiro e março de 2016.
} 
A existência dessas agroindústrias indica resistência à forte influência da cultura do tabaco na região e, consequentemente, à busca por alternativas de renda em que os sujeitos sejam mais independentes e menos subordinados às variáveis sobre as quais não possuem controle.

Para atender ao proposto, foram utilizadas como técnicas de pesquisa entrevistas em formato semiestruturado, pesquisa bibliográfica, pesquisa documental e observação in loco.

A análise e interpretação dos dados se basearam em Minayo (1992). O método apresenta como ponto de partida o interior da fala e, como ponto de chegada, a especificidade histórica e totalizante que produz a fala.

\section{Figura 1: Microrregião Norte do Corede do Vale do} Rio Pardo/RS

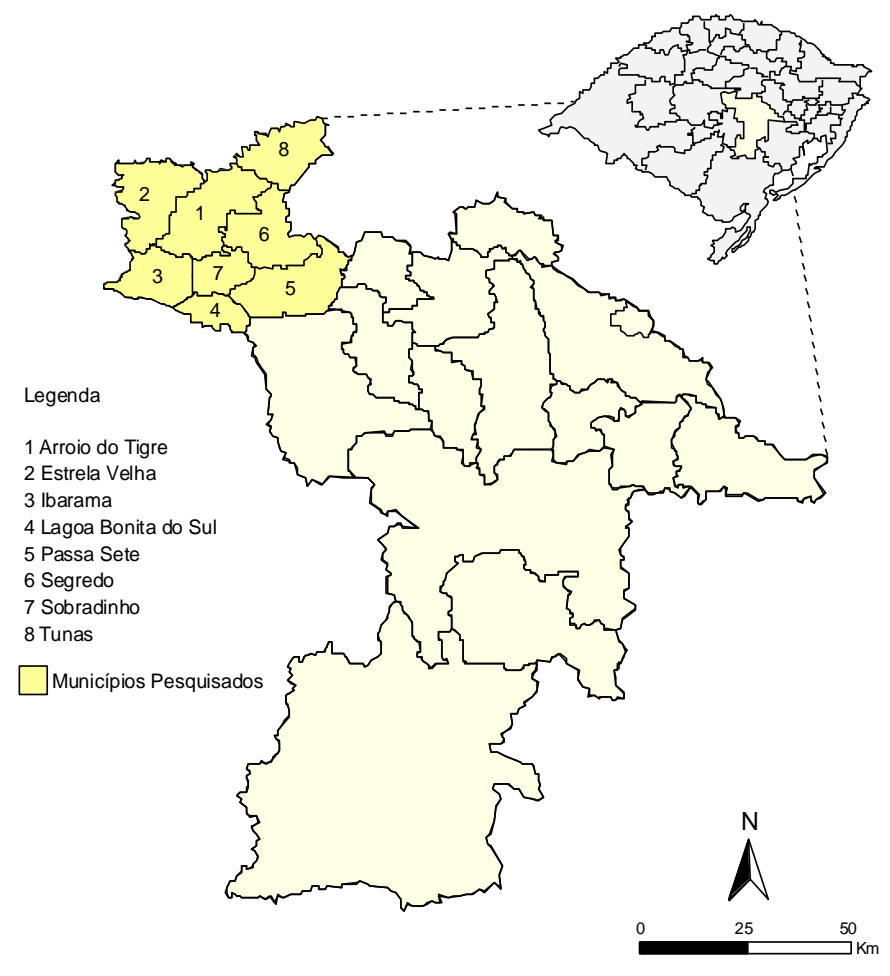

Fonte: FEE, 2009. Adaptado pela autora, 2016.

\section{Produção familiar de alimentos, tradição e resistência}

Chesnais (1996) destaca que a globalização é uma etapa específica e muito avançada do processo de internacionalização do capital. E esse processo é um dos movimentos estruturais do capitalismo.
Considerando que o processo de globalização está intimamente relacionado com o capitalismo, Harvey (2014) aponta que a resistência é uma reação à apropriação da vida cultural pelo capitalismo.

O autor destaca que "o capitalismo é expansionista e imperialista, a vida cultural, num número cada vez maior de áreas, vai ficando ao alcance do nexo do dinheiro e da lógica da circulação do capital. $\mathrm{Na}$ verdade isso provocou reações que vão da raiva e da resistência à tolerância e à apreciação" (HARVEY, 2014, p. 308).

No contexto da alimentação, Poulain (2013) afirma que, ao longo do tempo, houve o aumento da capacidade no que se refere às técnicas de conservação, de acondicionamento e de transporte. Isso transformou o mercado de alimentos, pois foi possível a distribuição de alimentos como congelados e enlatados por todo o planeta.

Para Roberts (2009, prólogo),

\begin{abstract}
A grande transformação da agricultura e do processamento de alimentos que teve início nos Estados Unidos após a segunda Guerra Mundial gerou maior produtividade e menores preços, mas também praticamente destruiu a cultura rural, que o país afirma ser a base de muitos de seus valores. Trinta anos mais tarde, a ascensão de varejistas de supermercados como o Wal-Mart diminuiu ainda mais os preços e, ao mesmo tempo, acabou com uma geração de pequenos agricultores e comerciantes de bairro e deixou o setor alimentício nas mãos de poucos atores globais e muito poderosos.
\end{abstract}

Toda essa mudança no cenário alimentar fez com que se efetivasse um movimento chamado internacionalização da alimentação. Com o advento dessas novas práticas desempenhadas pelas empresas agroalimentares transnacionais, pode ser constatado que "o alimento moderno está deslocado, ou seja, desconectado de seu enraizamento geográfico e das dificuldades climáticas que lhe eram tradicionalmente associadas" (POULAIN, 2013, p. 27).

A produção e a preparação dos alimentos foram transferidas a terceiros que apenas se preocupam com a diminuição dos custos e o aumento 
dos lucros. Nesse sentido, Roberts (2009, prólogo) sugere:

Não se trata de um apelo para que nos tornemos novamente produtores; contudo, trata-se de uma sugestão de que há algo de muito errado quando ninguém é produtor, quando ninguém é cozinheiro e quando o mais próximo que se chega de produzir uma refeição é no bufê do restaurante a quilo.

A mundialização e a industrialização no âmbito alimentar trouxeram a padronização e a homogeneização. Nessa conjuntura, a alimentação tradicional fica de lado e as empresas apostam cada vez mais em lanches portáteis, prontos para serem consumidos em qualquer horário e em qualquer lugar (ROBERTS, 2009).

Assim, o alimento perde a centralidade e se torna secundário. Para Roberts (2009, p. 45), "o futuro do alimento é ser um acessório". De acordo com o autor, as práticas e os alimentos tradicionais não dão certo no setor alimentício moderno. Isso acontece porque as preparações se tornaram automatizadas e a comida teve que ser ajustada aos processos industriais.

Roberts (2009) esclarece que, em alguns casos, esses ajustes são relativamente moderados, mas em outros, a mudança é tão drástica que altera a estrutura molecular do alimento. O autor considera correções relativamente moderadas casos como a desidratação do leite e o congelamento de carnes. 0 fato é que mesmo esses processos não modificando a estrutura molecular do alimento, eles interferem no sabor, no aroma e na tateabilidade. Isso significa dizer que a sensação organoléptica de uma comida tradicional se altera consideravelmente quando são utilizados insumos provenientes da indústria ao invés de insumos naturais, isto é, da forma como estão dispostos na natureza.

A cuca industrializada, por exemplo, quando está na mesa do consumidor final, não carrega o aroma do forneamento, a crocância da farofa, possui aditivos químicos, a massa, quando precisa ser sovada, conta com instrumentos mecanizados, 0 forneamento é realizado em fornos elétricos ou a gás e jamais em fornos a lenha, como dita a tradição, além de outras adaptações.

Não se trata somente de substituir processos e utilizar insumos provenientes da indústria. Trata-se da destruição das características naturais dos insumos e a adição de sintéticos para que a preparação apresente sabor, aroma, coloração e textura semelhantes aos naturais. Roberts (2009, p. 45) explica:

As empresas também começaram a usar aditivos para reparar o dano causado ao alimento durante a fabricação. Nas farinhas, as vitaminas e os minerais destruídos pelo branqueamento foram repostos, um processo que as empresas chamam de fortificação. As cores desbotam dos legumes e carnes durante o cozimento ou a pulverização e, portanto, os alimentos precisavam ser realçados; a clorofila confere novamente 0 verde às ervilhas em lata, ao passo que o caramelo empresta um dourado mais saudável e caseiro às carnes cozidas na pressão. $O$ sabor também precisa ser ressuscitado. O sabor natural é facilmente danificado pelo calor e por outros rigores do processamento; apenas 3\% do sabor de um biscoito permanecem após sair do forno e grande parte é absorvida pela embalagem. Algumas perdas de sabor podem ser minimizadas por mudanças no processo de fabricação; por exemplo, atualmente, muitas padarias comerciais pulverizam flavorizantes nos biscoitos e outros confeitos após terem sido assados, a fim de evitar o dano causado pelo calor. Mas o método mais fácil e simplesmente realçar o sabor sinteticamente.

São questões como as apresentadas pelo autor que colocam em xeque o título de comida ao produto alimentar industrializado. As transformações impostas pela indústria ultrapassam a perspectiva da tradição e interferem em outros campos, como a saúde das pessoas.

No mesmo sentido, Pollan (2008, p. 147) mostra que "a industrialização de nossa alimentação que chamamos de dieta ocidental está sistemática e deliberadamente minando as culturas tradicionais em toda parte. Isso pode ser tão destrutivo para nossa saúde como qualquer deficiência nutricional”.

Para Roberts (2009, p. 323), perde-se algo profundo em nossa vida "ao delegar a produção de alimentos aos outros, ao permitir que os parâmetros e prioridades do que comemos e como pensamos 
acerca disso sejam determinados cada vez mais por um modelo econômico bastante remoto". Está-se deixando de lado uma ligação importante porque a relação entre nós e o "reino físico, natural" tem se dado, por milênios, por meio da alimentação.

É nessa perspectiva que a tradição se apresenta como resistência. Ela se manifesta como um fator de reflexão frente às transformações provocadas pelos mecanismos globais de dominação. Chega o momento de demonstrar por meio de ações cotidianas que não se quer comer pães com sabor parecido com o de pão, quer-se comer o pão tradicional, feito com ingredientes naturais. Isso simboliza um "não" à dominação, um "não" à desconsideração de particularidades pelos atores hegemônicos.

Poulain (2013) esclarece que os particularismos nacionais e regionais são muito fortes e as sociedades transnacionais da alimentação são obrigadas a contar com este aspecto. Um exemplo disso é o McDonald's, ícone da homogeneização, que se adapta aos mercados locais.

Na França, por exemplo, serve-se cerveja nos restaurantes McDonald's, enquanto que, nos Estados Unidos, há apenas bebidas não alcoolizadas. Na França, na Holanda, na Bélgica... a maionese sempre acompanha as batatas fritas, enquanto que nos Estados Unidos o ketchup é o rei nesse uso (LUPTON, 1996, p. 94). A adaptação mais surpreendente é, sem dúvida, a criação para os mercados franceses, de um hambúrguer particular denominado royal... parece que no país da Revolução temos estranhas nostalgias. Em Quebec, todas as batatas fritas regadas ao molho pardo e de queijo procuram parecer com a poutine. Regularmente, pequenos truques transformam a lagosta canadense em Mchomard... (POULAIN, 2013, p. 29).

No que se refere à homogeneização e à resistência no contexto alimentar, um exemplo bastante ilustrativo é oferecido por Bacelar (2008, p. 2):

Um exemplo que eu gosto de dar é a França. O padrão hegemônico da distribuição de alimentos é, sem dúvida, o padrão supermercado. O Brasil, que gosta de copiar os Estados Unidos, adotou fortemente esse padrão. Por isso, estamos acabando com nossas feiras, com nossas mercearias.
Qualquer cidade média brasileira quer ter hoje seu supermercado. No entanto, em Paris continua havendo feira, continuam funcionando as pequenas lojas de alimentos. De onde vem isso? Vem da cultura do povo francês, que resiste ao padrão hegemônico, que não aceita 0 supermercado, que se recusa a estocar alimentos, que gosta de comprar, de loja em loja, o alimento fresco que vai ser consumido no dia ou no dia seguinte. Há supermercado? Há. Mas na periferia, para os estrangeiros. Os franceses continuam fazendo courses, como eles dizem. Então, a cultura, a visão de mundo tem sua influência, não há uma fatalidade.

Nesse contexto, Zaneti (2015) acrescenta que há um movimento contraditório entre globalização e regionalização. Para a autora, a globalização tende a padronizar os produtos e a regionalização se apresenta como uma reação que nega a padronização e fortalece as fronteiras culturais.

Desse modo, nem só a projeção global dos alimentos, nem só as cozinhas regionais ancoradas na tradição são forças únicas e dominantes. Ambas constituem uma contraposição de forças que, apesar de divergentes, interferem uma na outra.

Para Roberts (2009, p. 312), a alimentação sob o ponto de vista regional apresenta barreiras abrangentes. "Os pequenos agricultores perto das áreas urbanas sofrem pressão econômica intensa do desenvolvimento; os sistemas de distribuição são inadequados ou inexistentes", além disso, o autor explica que a produção de alimentos regionais precisa ultrapassar os consumidores "sofisticados e ativistas" e atingir os populares.

Mas, em um futuro não muito distante, no qual os preços da energia sejam altos e as ansiedades dos consumidores acerca da segurança alimentar não tenham diminuído, os defensores dos alimentos regionais dizem que essas barreiras cairão. As preocupações acerca da obesidade e o estado deplorável da nutrição infantil já levaram muitas escolas públicas a começar a comprar alimentos produzidos localmente para seus programas de alimentação escolar - uma tendência que os defensores dos alimentos regionais estão se empenhando em expandir. (ROBERTS, 2009, p. 312).

No entanto, a globalização não deixa de ser considerada uma ameaça à sobrevivência das tradições alimentares. A partir do advento do 
capitalismo, da internacionalização do capital e da própria globalização, estabeleceram-se lutas simbólicas entre os interesses hegemônicos na busca pelo capital e entre aqueles que procuram preservar seus traços culturais tradicionais.

Eventos como a produção de alimentos tradicionais podem ser encarados como manifestações simbólicas não só contra a homogeneização alimentar, mas contra o modo de produção capitalista.

Poulain (2013, p. 33) esclarece que "as tradições alimentares, na sua função emblemática, tornam-se um lugar de resistência cultural", pois historicamente o consumo de produtos caros e distantes, como é o caso das especiarias, indica uma posição social, a da nobreza. A valorização da tradição popular ligada aos alimentos está intimamente amarrada à industrialização dos alimentos, estando relacionada ao risco de diluição das identidades.

Compreender o espaço social alimentar permite entender a complexidade do processo dos modelos alimentares, em uma perspectiva geral. Os modelos alimentares incluem questões como a escolhas dos alimentos a partir da perspectiva orgânica do homem, da disponibilidade pelo ambiente natural, da conexão do homem com a natureza e por razões culturais, entre outras (POULAIN, 2013).

Perceber os critérios selecionados pelos sujeitos no tocante ao espaço social alimentar permite compreender o quanto os saberes vinculados à região se contrapõem à homogeneização alimentar.

Morin (1997) destaca que a relação entre culturas alimentares e resistência teve início no final dos anos 1960, quando surge, em oposição ao crescimento contínuo e ao progressismo desenfreado, um movimento que se volta aos valores da natureza, valorizando os pratos rústicos e naturais, como os cozidos, os pães do campo, a broa de manteiga, os assados em fogão a lenha...

Para o autor, a simplicidade rústica é valorizada e um novo ordenamento passa a vigorar. Até o momento, a alta gastronomia divergia dos alimentos rústicos, mas, a partir deste período a alta gastronomia e a gastronomia rústica contestaram a alimentação industrializada.

A partir de 1980, o movimento se ampliou e se regionalizou. Ações que valorizavam a cozinha regional se tornaram populares. Teve início, então, uma forte ligação entre o turismo e o campo alimentar, onde a França, embrionariamente, atraiu turistas por meio da culinária tradicional (POULAIN, 2013).

A partir dessa conjuntura é relevante afirmar que: "A alimentação tem uma função estruturante na organização social de um grupo humano." (POULAIN, 2013, p. 17). O campo alimentar ultrapassa os aspectos inerentes à própria alimentação e carrega consigo um significado. Contextualizar historicamente as questões intrínsecas à alimentação é de suma importância para que seja compreendido o sentido expresso.

$\mathrm{Na}$ perspectiva desta pesquisa, a tradição alimentar é encarada como resistência à globalização, a produção de alimentos pelas agroindústrias familiares, em um contexto adverso, também é considerada uma reação. A resistência se dá, acima de tudo, a um "conjunto de normas e parâmetros generalizados que governam todas e quaisquer práticas locais e específicas" (PLOEG, 2008).

Hobsbawm (2014) esclarece que as tradições são reações a situações novas, isto é, são meios de resistir às transformações do mundo. Nesse sentido, as tradições não são somente práticas aleatórias que remetem ao passado, mas são ações que se referem ao passado e que carregam significados frente às situações em que estão postas.

No mesmo sentido, Silva e Silva (2009, p. 406) reforçam:

Para Hobsbawm, uma das características das tradições inventadas é que elas estabelecem uma continuidade artificial com o passado, pela repetição quase obrigatória de um rito. As tradições têm como função legitimar determinados valores pela repetição de ritos antigos (ou de ritos definidos como antigos, no caso das tradições inventadas), que dariam uma origem histórica a determinados valores que devem ser aceitos por todos e se opõe a costumes novos. 
Por tradição alimentar, entende-se a produção de alimentos identificados como produtos com história, pois se constituem e fazem parte de uma determinada cultura, sendo produzidos com matériaprima de uma determinada região. Devido aos conhecimentos e ao saber-fazer presentes nesses alimentos, através de gerações, a sua produção resgata não só a história envolta neles, mas o caráter histórico da agricultura familiar.

Nesta pesquisa, o termo "tradição alimentar" se torna apropriado no atendimento aos objetivos propostos, pois incita a investigar as simbologias expressas nos alimentos produzidos nas agroindústrias familiares.

É oportuno esclarecer que a tradição é praticada e compartilhada por um grupo capaz de proporcionar continuidade às práticas tradicionais, sendo possível a escolha dos sujeitos aptos à atividade. Nesse sentido, as tradições podem ser seletivas, caracterizando reconhecimento entre os sujeitos de um mesmo grupo e restrição aos diferentes.

Sob outra perspectiva, a simples existência de movimentos que defendem a tradição já declaram que a própria tradição foi rompida, necessitando, por meio da ação destes movimentos, ser recuperada ou preservada (HOBSBAWM, 2014). Nesse sentido, o resgate de práticas esquecidas se efetiva por meio da tradição contrapondo-se aos efeitos da globalização no território.

Hobsbawm (2014, p. 21) aponta que "o estudo das tradições esclarece bastante as relações humanas com o passado [...]. Isso porque toda tradição inventada, na medida do possível, utiliza a história como legitimadora das ações e como cimento da coesão grupal”.

Nesse contexto, a investigação da tradição no recorte das agroindústrias familiares produtoras de alimentos na Microrregião Norte do Corede do Vale do Rio Pardo mostra o significado da tradição alimentar enquanto prática cotidiana.

A tradição alimentar enquanto prática carregada de significados não está separada do contexto global. O acesso a grande diversidade de alimentos é capaz de interferir na tradição. Por trás da oferta variada dos alimentos em diferentes espaços está a mundialização e industrialização no âmbito alimentar, trazendo a padronização e homogeneização (POULAIN, 2013).

Como já citado, Hobsbawm (2014) situa a tradição nas sociedades tradicionais. Brandão (2015), por sua vez, oferece um contraponto diferenciando sociedade de comunidade. Para o último

\begin{abstract}
parece haver um consenso de que sociedade é o lugar mais abstrato, abrangente, institucional, contratual e impositivo de que necessariamente se é, em que se vive. O lugar humano no qual se pertence de maneira inevitável, por dever a instituições e direitos derivados delas. Enquanto a comunidade - e elas são bem mais variadas e diferenciadas que as sociedades - é o lugar mais humanamente concreto, delimitado, interpessoal, consensual e livre. O lugar da escolha, a que voluntariamente (mas não tanto, sabemos) aderimos e ao qual pertencemos por escolha, herança, direito derivado de/entre pessoas, e por dever devido a pessoas, grupos e redes de interpessoas. (BRANDÃO, 2015, p. 25).
\end{abstract}

Durhan (2004) trata o conceito de comunidade a partir de duas perspectivas: a partir do senso comum e a partir da sociologia. Para a autora,

$\mathrm{Na}$ linguagem comum, a noção de comunidade refere-se a uma coletividade na qual os participantes possuem interesses comuns estão afetivamente identificados uns com os outros. Essa ideia, que pressupõe harmonia nas relações sociais, é altamente valorizada, constituindo, por assim dizer, o ideal da vida social. É neste sentido que a comunidade aparece como um mito em nosso tempo, pois o ideal que ela apresenta opõe-se a realidade do conflito de interesses e da impessoalidade das relações sociais própria da nossa sociedade. Na sociologia, o conceito de comunidade adquire grande importância por meio da obra de autores alemães, particularmente a partir de Ferdinand Tonnies, apresentando-se sempre como um dos polos de uma dicotomia, em oposição ao conceito de sociedade. É sempre nestes termos que ela deve ser entendida. (DURHAN, 2004, p. 221).

Assim, fica claro que, conceitualmente, a comunidade, onde a tradição está ancorada, é caracterizada pela contradição e pelo conflito. De acordo com Durhan (2004, p. 222), na comunidade, 
coexistem interesses divergentes com "o sentimento subjetivo que têm os participantes de constituírem um todo".

A tradição é o elemento que vai caracterizar a contradição e o conflito, pois ela retoma o residual como forma de negação a práticas hegemônicas que foram introduzidas no espaço.

A ação dos atores hegemônicos no contexto do modo de produção capitalista exclui aqueles que não seguem a produção de commodities, geralmente os agricultores familiares. Na proposta hegemônica a noção de desenvolvimento é remetida ao agronegócio, sendo que a manifestação de aspectos tradicionais vai de encontro ao conceito de desenvolvimento.

A expressão da tradição em um espaço marcado pelo amplo favorecimento do agronegócio indica oposição ao que chegou e se estabeleceu no espaço. A tradição vai se colocar de maneira inovadora e rentável quando busca alternativas às exigências dos atores hegemônicos.

Diegues (2000, p. 22), no intuito de conceituar as sociedades tradicionais, reforça a oposição desses grupos a outros, muitos deles oportunizados pela conjuntura hegemônica.

Estamos utilizando a noção de "sociedades tradicionais" para nos referirmos a grupos humanos culturalmente diferenciados que historicamente reproduzem seu modo de vida, de forma mais ou menos isolada, com base em modos de cooperação social e formas específicas de relações com a natureza, caracterizados tradicionalmente pelo manejo sustentado do meio ambiente. Essa noção se refere tanto a povos indígenas quanto a segmentos da população nacional que desenvolveram modos particulares de existência, adaptados a nichos ecológicos específicos. Exemplos empíricos de populações tradicionais são as comunidades caiçaras, os sitiantes e roceiros tradicionais, comunidades quilombolas, comunidades ribeirinhas, os pescadores artesanais, os grupos extrativistas e indígenas. Exemplos empírico de populações não-tradicionais são os fazendeiros, veranistas, comerciantes, servidores públicos, empresários, empregados, donos de empresas de beneficiamento de palmito ou outros recursos, madeireiros, etc.

No contexto, é visível a contraposição entre grupos humanos que produzem seu modo de vida a padrões estabelecidos por fatores externos. As sociedades tradicionais como nomeia Diegues (2000), organizam sua maneira de viver baseada no conhecimento tradicional. Segundo o autor, o conhecimento tradicional "é definido como o conjunto de saberes e saber-fazer a respeito do mundo natural, sobrenatural, transmitido oralmente de geração em geração" (DIEGUES, 2000, p.30).

No entanto, Cunha (2007), no que diz respeito ao conhecimento tradicional, declara que ele não é apenas um repositório de conhecimentos transmitidos de geração em geração, mas são conhecimentos que continuam a ser produzidos de modo específico, ou seja, por meio de protocolos e métodos próprios.

Assim, cabe destacar que o conhecimento tradicional, base das comunidades tradicionais, ultrapassa a característica de ser transmitido através de gerações e inclui o modo peculiar de ser praticado.

Brandão (2015) qualifica as comunidades tradicionais com seis características que se adequam à produção de alimentos nas agroindústrias familiares. A primeira delas se refere à transformação da natureza. A transformação da natureza é um trabalho realizado sem interrupções ao longo de gerações e está "associado a um saber peculiar que, com mínimos recursos econômicos, empresariais e tecnológicos, se comparados com os das neounidades do agronegócio, tornaram um espaço de natureza em um lugar social humanamente habitável e, em seus termos próprios, produtivo" (BRANDÃO, 2015, p. 73).

De acordo com a primeira característica, é possível constatar que o trabalho nas agroindústrias familiares transforma os insumos em alimentos de modo eficiente, ou seja, com menor uso de recursos se comparado a outros setores produtivos. Assim, as agroindústrias familiares de alimentos não interferem de maneira ameaçadora no ambiente natural, a ponto de descaracterizá-lo.

Como segunda característica menciona a autonomia. O trabalho realizado conta com graus de autonomia bem maiores se comparados "com os peões de fazenda, com os empregados de empresas 
rurais e com os trabalhadores assalariados da/na cidade" (BRANDÃO, 2015, p. 75).

No que se refere à autonomia, o autor ainda complementa:

Trabalhar no que é seu; ser dono do seu tempo de trabalho; ser livre (mesmo que em termos relativos) para decidir o destino de sua produção de bens da terra, ou mesmo de artesanato; enfim, trabalhar sem patrão, mesmo que na lida do pobre são qualificadores altamente valorizados. Eles desenham um modo de vida em que muitas vezes o preço de uma assumida condição de pobre é a realização de uma autonomia, traduzida como uma espécie sempre desejada de liberdade: ser dono do seu e, por meio desse, ser dono de sua vida. (BRANDÃO, 2015, p. 75-76).

Essa característica reconhece a independência na gestão da propriedade rural. Gerir e colher os frutos do trabalho sem obedecer a regras externas valoriza o trabalhador, tornando-o sujeito de sua própria história.

A terceira característica elencada se refere à autoctonia e reporta-se à ideia de herdar nomes, tradições e lugares socializados (BRANDÃO, 2015). A propriedade rural familiar é, na maioria dos casos, passada de geração para geração, assim como as tradições. A herança do lugar e do saber-fazer são exemplos de autoctonia nas propriedades rurais onde estão instaladas as agroindústrias familiares produtoras de alimentos.

A quarta característica faz referência à memória de lutas passadas de resistência. Brandão (2015) identifica a comunidade tradicional não apenas pelo seu modo de vida diferenciado, mas também pelo fato de que as gerações têm vivenciado lutas, sofrimento, ameaça e resistência. $\mathrm{O}$ autor argumenta que essa peculiaridade não fez parte somente do passado, mas ainda é atual.

Historicamente, os imigrantes europeus, na fuga de um sistema opressor e excludente, chegaram ao Brasil em busca de melhores condições de vida. Atualmente, seus descendentes, depois de passadas muitas décadas, têm sua autonomia de sujeitos no território impedida por atores hegemônicos que, no presente, ameaçam, expropriam, cercam e conflitam. Esse exemplo demonstra que as lutas de resistência marcaram o passado e continuam definindo 0 presente.

O quinto aspecto evidencia mais fortemente a história de lutas e resistências atuais. Faz alusão à memória de lutas passadas que ainda é vivida no presente e a transformação de lugares onde vivem comunidades em espaços destinados a reservas biológicas e a parques naturais.

Finalmente lembremos as ameaças de expropriação ou de transformações rápidas e de efeitos direto sob o modo de vida tradicional, provindas de frentes pioneiras, por meio das diferentes modalidades da expansão do capital sob a forma de fazendas/empresas de monoprodução de gado de corte, de vegetais de transformação (milho, cana-deaçúcar) ou e exportação direta (soja). Ou ainda como empresas madeireiras ou mineradoras, cujos desastrosos efeitos sobre biomas como a floresta ou o Cerrado são conhecidos e com frequência denunciados. (BRANDÃO, 2015, p. 79).

O autor apresenta três exemplos que envolvem a questão da história de lutas e resistências atuais. $\mathrm{O}$ último exemplo, de modo particular, traduz o rural da Microrregião Norte do Corede do Vale do Rio Pardo, onde a expansão do capital transforma o modo de vida tradicional.

Brandão (2015) sublinha a experiência da vida em territórios cercados e ameaçados. São territórios cercados e ameaçados porque estão ilhados em terras consideradas pouco férteis pelos expropriadores. São índios, quilombolas e camponeses vivendo sob o peso de contínuas ameaças, resistindo e procurando serem percebidos.

O conjunto dessas características qualifica as comunidades tradicionais:

Assim sendo, elas não são tradicionais porque aos olhos de quem chega opõem-se ao que, segundo eles, é moderno. São tradicionais porque são ancestrais, porque são autóctones, porque são antigas, resistentes e anteriores. Porque possuem uma tradição de memória de si mesmas em nome de uma história construída, preservada e narrada no existir em um lugar, por oposição a quem chega de fora, e à neo-história do chegante. (BRANDÃO, 2015, p. 80). 
No campo dos grupos tradicionais, a tradição carrega as noções de previsão e segurança. Conforme Bornheim (1987, p. 18):

\begin{abstract}
A vontade da tradição está em querer-se tradição, e ela se quer tão totalmente tradição que se pretende eterna, determinando não apenas o passado e o presente, mas o próprio futuro, portanto tudo pode ser previsto, exigese a antecipação: tudo vai ser sempre fundamentalmente idêntico, sem percalços com o possível surto da alteridade. A tradição se pretende, assim, uma grande segurança nós estamos na própria segurança, vivemos numa resposta e estamos assegurados nela, ela é nosso princípio.
\end{abstract}

A segurança e a previsão são asseguradas pela tradição e se tornam um recurso à ruptura (BORNHEIM, 1987). Os agricultores familiares, nesta pesquisa, utilizam a tradição como um mecanismo que garante a reprodução do seu modo de vida.

A ruptura se apresenta como uma maneira de interromper a reprodução da lógica dos agricultores familiares, que é ameaçada por imposições hegemônicas globais. Assim, o modelo produtivista, baseado na exploração dos recursos naturais, ameaça valores como a autonomia e sucessão entre gerações.

A incompatibilidade entre a lógica produtivista e a lógica preservada pela agricultura familiar gera tensionamentos e faz com que as tradições tenham que se adaptar. "A adaptação, por vezes, surge para conservar velhas práticas em condições novas ou usar modelos antigos para novos fins." (WERLE, 2014, p. 128).

Maia (2001, p. 91) destaca que uma característica da sociedade tradicional é a estabilidade, "em que a tradição agiria com 'uma força retardadora' que impediria a atuação das mudanças". Dessa maneira, os agricultores familiares, em um contexto adverso, protegem-se das mudanças que consideram prejudiciais ao seu modo de vida. Nesse sentido, Oliven (1992) mostra que as tradições são evocadas nos períodos de mudança social.

É preciso, portanto, esclarecer que tradição não é sinônimo de "relíquia", "antigo" e "atraso". Bages (1981) mostra que a tradição inclui a ideia de movimento e não se contrapõe a renovação.

\section{A tradição alimentar na microrregião norte do COREDE do Vale do Rio Pardo}

Com o propósito de analisar de que modo a tradição alimentar manifesta-se nas agroindústrias familiares da Microrregião Norte do Corede do Vale do Rio Pardo, buscou-se através das entrevistas realizadas compreender o contexto no qual surgiram as agroindústrias familiares da região pesquisada e qual o significado da tradição alimentar no contexto em que estão inseridas.

O Quadro 1 mostra que $75 \%$ das famílias explicaram que o motivo específico que propiciou a criação e formalização da agroindústria de alimentos foi resultado da interferência da conjuntura global. Segundo os dados apresentados, 25\% das famílias atribuíram a outras causas, que não as de ordem global, os motivos que propiciaram a criação da agroindústria familiar. Assim, é possível observar que a interferência global na região é três vezes maior em relação aos outros motivos apresentados.

Santos (2000) apresenta a globalização como perversidade. A partir dessa perspectiva, consequências indesejáveis provocadas pelo processo de globalização se manifestam no território. O autor cita, como exemplo, consequências como a pobreza, a fome, o desemprego, a inacessibilidade da educação de qualidade, entre outros.

A partir desta pesquisa, é possível concluir que $75 \%$ dos motivos citados para a criação de agroindústrias familiares são resultados do processo de imposição da globalização, pois são consequências perversas advindas de ações globais comandadas por atores hegemônicos.

De acordo com Etges (2001, p. 360), o Vale do Rio Pardo é um

território monopolizado pelas empresas transnacionais fumageiras, a Região do Vale do Rio Pardo destaca-se por ser fortemente homogeneizada, tendo em vista que o oligopsônio fumageiro controla e centraliza todo o processo relativo à produção de tabaco: desde as técnicas utilizadas no cultivo, à comercialização da matéria-prima, ao seu beneficiamento e à sua 
industrialização, que resulta na produção de cigarro.

Entre as consequências perversas que o cultivo de tabaco provoca está o suicídio, o endividamento, a intoxicação, a depressão, a ansiedade e a irritação (GIRARDI, 2016). Essas características foram confirmadas pelas famílias entrevistadas, pois as mesmas citaram, como motivo declinante para o cultivo da cultura, intoxicação, doença na coluna, endividamento, trabalho excessivo e geração de renda insatisfatória.

Cabe ressaltar que romper com a produção de tabaco depende de iniciativas empreendedoras da família, "pois os produtores muitas vezes estão desacostumados a enfrentar um mercado instável, uma vez que a 'facilidade' da garantia de compra da produção pelas empresas do tabaco acaba por inibir a iniciativa destes produtores, na busca de novos mercados para seus produtos" (KARNOPP, 2014, p. 145).

Quadro 1: Motivação que impulsionou a criação das agroindústrias familiares

\begin{tabular}{|c|c|c|c|}
\hline Categoria & $\%$ & Agroindústria & Variável \\
\hline \multirow{7}{*}{$\begin{array}{c}\text { Interferência } \\
\text { da } \\
\text { conjuntura } \\
\text { global }\end{array}$} & \multirow{7}{*}{$75 \%$} & 1 & $\begin{array}{l}\text { Intoxicação } \\
\text { por agrotóxico } \\
\text { utilizado no } \\
\text { cultivo de } \\
\text { tabaco; }\end{array}$ \\
\hline & & 2 & $\begin{array}{l}\text { Intoxicação } \\
\text { por agrotóxico } \\
\text { utilizado no } \\
\text { cultivo de } \\
\text { tabaco; }\end{array}$ \\
\hline & & 3 & $\begin{array}{l}\text { Doença na } \\
\text { coluna } \\
\text { ocasionado } \\
\text { pelo cultivo de } \\
\text { tabaco; }\end{array}$ \\
\hline & & 4 & $\begin{array}{l}\text { Endividamento } \\
\text { ocasionado } \\
\text { pelo cultivo de } \\
\text { tabaco; }\end{array}$ \\
\hline & & 5 & $\begin{array}{l}\text { Alternativa } \\
\text { para a } \\
\text { produção de } \\
\text { tabaco; }\end{array}$ \\
\hline & & 6 & $\begin{array}{l}\text { Crise na } \\
\text { venda de } \\
\text { suínos; }\end{array}$ \\
\hline & & 7 & $\begin{array}{l}\text { Crise na } \\
\text { venda de } \\
\text { suínos; }\end{array}$ \\
\hline
\end{tabular}

\begin{tabular}{|c|c|c|l|} 
& & 8 & $\begin{array}{l}\text { Menos } \\
\text { trabalhoso e } \\
\text { venda } \\
\text { garantida; }\end{array}$ \\
\cline { 2 - 4 } & & 9 & $\begin{array}{l}\text { Alternativa } \\
\text { que tivesse } \\
\text { demanda e } \\
\text { gerasse renda } \\
\text { satisfatória; }\end{array}$ \\
\hline $\begin{array}{c}\text { Formalização } \\
\text { de uma } \\
\text { prática }\end{array}$ & $\mathbf{1 7 \%}$ & 10 & $\begin{array}{l}\text { Gosto } \\
\text { pessoal; }\end{array}$ \\
\cline { 2 - 4 } & & 11 & $\begin{array}{l}\text { Produção era } \\
\text { constante na } \\
\text { propriedade; }\end{array}$ \\
\hline Demanda & $\mathbf{8} \%$ & 12 & $\begin{array}{l}\text { Demanda de } \\
\text { clientes já } \\
\text { fidelizados; }\end{array}$ \\
\hline TOTAL & $\mathbf{1 0 0 \%}$ & $\mathbf{1 2}$ & \\
\hline
\end{tabular}

Fonte: Elaborado pela autora, 2016.

No que se refere à formalização das agroindústrias familiares, a pesquisa revelou que $8 \%$ dos estabelecimentos foram formalizados entre os anos de 2000 e 2005, 25\% entre 2006 e 2010 e 67\% das agroindústrias familiares foram formalizadas entre 2011 e 2015.

Foi possível perceber que entre os anos 2006 e 2010, surgiu na região um movimento em prol da formalização de agroindústrias familiares. Esse movimento ganhou mais força nos cinco anos subsequentes.

A formalização de $67 \%$ das agroindústrias familiares entre 2011 e 2015 pode ser explicada por meio da implementação da Política Estadual de Agroindústria Familiar no Estado do Rio Grande do Sul.

Em janeiro de 2011 o governo do Estado passou a implementar a criação de políticas públicas voltadas à agricultura familiar. Nesta época o Rio Grande do Sul contava com 8.160 agroindústrias familiares, sendo que apenas 560 estavam formalizadas. Com base nesses dados foi dado início à Política Estadual de Agroindústria Familiar.

Um dos objetivos dessa política é ampliar o número de agroindústrias familiares formalizadas. A região pesquisada ainda apresenta um número de agroindústrias familiares informais maior em relação às agroindústrias formais, no entanto, certamente, este intervalo foi reduzido com a implementação da política. 
O Quadro 2 mostra os produtos alimentares provenientes das agroindústrias familiares pesquisadas.

A partir da observação dos produtos agroindustriais provenientes da região pesquisada foi possível verificar que estes possuem forte ligação com a origem étnica das famílias. No entanto, nem todas as famílias expressam tradição na produção agroindustrial, pois, apesar do produto ser típico, ele não é tradicional. Neste caso, a agroindústria familiar é concebida mais como um negócio que, ancorado na historicidade, busca oportunidades, como demanda e pouca concorrência.

\section{Reinhardt (2007, p. 134) mostra que}

as comidas típicas muitas vezes fazem parte da mesa cerimonial, tornando-se comida ritual, travestindo-se assim, em tradição culinária. Vamos deixar claro que nem toda comida típica é tradição culinária. Mas pode vir a ser. Isto irá depender do significado que a comida típica está trazendo. Eu posso estar comendo uma comida típica e nem por isso ela ser uma tradição culinária para mim.

Dois descendentes de alemães podem estar comendo um strudel de maçã por motivos diferentes. Dependendo destes motivos, o strude/ para um, pode ser apenas uma comida típica e para outro, uma tradição culinária. Um pode estar comendo o strudel de maçã por gostar e, por naquele momento, estar com vontade de comer um doce. Porém, para ele, esta iguaria pode não despertar nenhum outro sentimento que não seja o de sentir prazer e estar saciado: ou seja, ter um sentido, uma função prática.

Outro descendente pode estar comendo um strudel de maçã na festa de aniversário da mãe, que sempre faz esta preparação nesta data para comemorar com os amigos e familiares, para ser saboreado com um café com leite (sem açúcar, pois... o alemão não toma café com açúcar.). Neste caso, o strudel de maçã muda de status; agora é uma tradição culinária.

É interessante observar que as agroindústrias familiares que comercializam mel, pescado e mandioca distanciam-se dos preparos típicos de italianos e alemães.

A partir das informações dispostas no Quadro 2 , é possível perceber que $75 \%$ das agroindústrias pesquisadas produzem alimentos diretamente relacionados à origem étnica das famílias (alemã, italiana e luso-brasileira), e que $25 \%$ dos estabelecimentos trabalham com preparos que estão relacionados com a cozinha originalmente brasileira.
Quadro 2: Produto Agroindustrial

\begin{tabular}{|c|c|}
\hline Agroindústria & Produto \\
\hline$A$ & $\begin{array}{l}\text { Copa, salame, linguiça, salsichão, } \\
\text { carne in natura e carcaça suína }\end{array}$ \\
\hline B & $\begin{array}{l}\text { Salsichão, salame, copa, carne, } \\
\text { torresmo, banha e morcilha; }\end{array}$ \\
\hline \multirow{2}{*}{$\mathrm{C}$} & Linguiça, copa, salsichão e salame; \\
\hline & Biscoito colonial, cuca e pão; \\
\hline $\mathrm{D}$ & Mel; \\
\hline$E$ & Mandioca; \\
\hline $\mathrm{F}$ & Bolacha e massa caseiras; \\
\hline G & Filé, manta, peixe inteiro e em pedaços; \\
\hline $\mathrm{H}$ & $\begin{array}{l}\text { Carré, costela, salsichão, linguiça, } \\
\text { bacon, presunto, banha e medalhão; }\end{array}$ \\
\hline I & Pão, cuca, bolacha e torta; \\
\hline $\mathrm{J}$ & Massa caseira; \\
\hline $\mathrm{K}$ & Bolacha Caseira. \\
\hline
\end{tabular}

Fonte: Elaborado pela autora, 2016

A mandioca, o peixe e o mel estão fortemente ligados aos indígenas no Brasil e nunca se tornaram símbolos culinários do país. Sobre a formação da culinária brasileira, Dória (2014, p. 28) destaca que

nos países de história colonial, raramente se deu esse processo de construção de símbolos culinários com a capacidade de unificar toda população em torno de uma ementa, e a restauração do valor do passado é expediente recentíssimo. A razão disso é que nem sempre as respectivas burguesias conseguiram construir um terreno cultural em comum com os demais estratos e classes da população. Quase nunca quiseram se confundir com as populações nativas, mantendo como forte referencial de sua identidade a origem europeia, e, através de uma cultura letrada restrita, criaram uma

3 Carcaça suína, segundo a Associação Brasileira dos Criadores de Suínos, refere-se ao suíno morto, despojado de vísceras, inclusive rins e gordura dos rins, cerdas e unhas, permanecendo a cabeça, extremidade dos membros, couro e cauda. 
verdadeira dualidade sociocultural. Assim, índios, negros e europeus não foram reunidos sob os mesmos signos, a não ser depois da segunda década do século XX. Religião "de negro" e cozinha "de bugre" eram expressões que manifestavam a exclusão e, ainda que as várias etnias tenham se aproximado pouco a pouco, com o tempo, tiveram a função cultural ativa de diferenciar grupos dentro do que viria a ser nação.

Assim, é possível concluir que, na região pesquisada, manifesta-se o que o autor chama de dualidade sociocultural, pois são evidentes os dois tipos de preparos comercializados pelas agroindústrias, os de origem europeia e os essencialmente brasileiros.

No que tange à relação entre tradição e produção agroindustrial, foi possível concluir que $75 \%$ das famílias manifestam tradição na produção agroindustrial, pois o conhecimento presente na família, por meio do saber fazer, é aplicado na agroindústria de alimentos.

Os conhecimentos herdados dos antepassados são priorizados e, quando permitido pela legislação vigente, são colocados em prática. Uma família expôs que costuma preparar o produto agroindustrial para o consumo da família em separado, deixando de aplicar conservantes. Por causa da legislação sanitária relativa ao controle de alimentos, o mínimo de conservante permitido é adicionado aos produtos comercializados.

Dessa forma, o controle sanitário, na busca pela segurança alimentar, acaba interferindo na tradição alimentar. Como mostra Menezes (2011), muitas preparações tradicionais estão inseridas no mercado informal, por não cumprirem a legislação vigente. Assim, fica evidente que há contradição entre as "exigências sanitárias e as tradições de produção, consumo e circulação dos alimentos processados artesanalmente" (CINTRÃO, 2012, p.1).

Diante do grupo de entrevistados, 25\% não aplicam o saber presente no grupo familiar nas atividades agroindustriais. Assim, a agroindústria não manifesta tradição, mas ela resgata a tradição familiar. Isso acontece porque, mesmo que um produto com valor de uso não tenha se transformado num produto com valor de troca (MIOR, 2007), como acontece no primeiro caso, a produção agroindustrial é capaz de relembrar momentos vividos em família, quando esta participava de atividades de pesca ou quando o aroma da bolacha ocupava a casa na infância.

De modo geral, nos casos em que a tradição familiar não está presente nas atividades agroindustriais, as famílias encaram a agroindústria como uma estratégia de obtenção de renda.

Como já mencionado, 25\% das famílias deixaram claro que os produtos agroindustrializados não carregam tradição. Desse total, apenas uma família, o que corresponde a $8 \%$ do total de entrevistados, declarou que os produtos da agroindústria familiar não carregam significado algum e que a agroindústria é concebida como um negócio.

Os outros $17 \%$, mesmo expressando que a agroindústria não manifesta tradição, demonstram que ela carrega um significado. Assim, é possível concluir que, para 92\% dos entrevistados, a agroindústria familiar se posiciona de alguma maneira frente ao contexto global.

Para os entrevistados, os alimentos provenientes das agroindústrias familiares se diferenciam dos produtos alimentares provenientes da indústria por apresentarem qualidade. A partir das entrevistas, foi possível compreender que qualidade alimentar se resume à presença de características como sabor e maciez, além da utilização de ingredientes provenientes do meio rural.

\section{Considerações finais}

Nesta pesquisa evidenciou-se que o produto oriundo da agroindústria familiar é um alimento diferenciado e com qualidade. Essa produção se diferencia daquela que provém da indústria de alimentos e estas duas produções se colocam em extremos opostos.

Além da questão da qualidade alimentar, as famílias declaram que os alimentos agroindustrializados, diferentemente dos produtos alimentares oriundos da indústria, são saudáveis por não conterem aditivos químicos e sintéticos. 
Nessa perspectiva, as agroindústrias familiares de alimentos se apresentam como resistência à imposição de um padrão industrial de alimentação e podem ser entendidas como uma reação ao domínio atual dos mercados (PLOEG, 2008, p. 296). Para o autor, essas reações "funcionam como uma crítica simbólica e como uma alternativa ao tipo de conversões governadas pelos mercados que são centrais no Império. Elas podem de fato, ser vistas como atos de insubordinação relativamente ao império".

Ultrapassando a questão alimentar, as famílias destacaram que as atividades na agroindústria familiar são prazerosas. A questão da autonomia e a maior interação com a natureza se mostraram fatores determinantes neste quesito.

O vínculo da família com o produto agroindustrial foi muito enfatizado, demonstrando haver uma forte relação entre o saber-fazer e a opção por trabalhar com agroindústrias familiares. Essa relação resulta da possibilidade de escolha das famílias à medida em que optam pela atividade agroindustrial, por considerá-la mais aprazível para o grupo familiar. O prazer em fazer se torna presente, sendo fruto de uma escolha e não de uma imposição global.

\section{Referências}

BACELAR, Tânia. Globalização e território. Le Monde Diplomatique Brasil. São Paulo, jun. 2008. Disponível em: $<$ http://www.diplomatique.org.br/artigo.php?id=20 2>. Acesso em 20 jul. 2016.

BAGES, Josep Torras I. La tradición catalana. Barcelona: Edicions 62, 1981.

BORNHEIM, Gerd. O conceito de tradição. In: BORNHEIM, G. et al. Cultura brasileira: tradição e contradição. Rio de Janeiro: Jorge Zahar Editor/Funart, 1987.
BRANDÃO, Carlos Rodrigues. A comunidade tradicional. In: UDRY, C.; EIDT, J. S.; Editoras Técnicas. Conhecimento tradicional: conceitos e marco legal. Brasília: Embrapa, 2015.

CHESNAIS, François. A mundialização do capital. São Paulo: Xamã, 1996.

CINTRÃO, Rosângela Pezza. Comida, vigilância sanitária e patrimônio cultural: conflitos e contradições entre políticas públicas. In: I Seminário sobre alimentos e manifestações culturais tradicionais. Sergipe, 2012.

CUNHA, Manuela Carneiro da. Relações e dissensões entre saberes tradicionais e saber científico. Revista da USP, São Paulo, n. 75, p. 76-84, set./nov. 2007.

DIEGUES, Antonio Carlos (Org.). Os saberes tradicionais e a biodiversidade no Brasil. São Paulo: Ministério do Meio Ambiente; Coordenadoria da Biodiversidade; Universidade de São Paulo, 2000.

DÓRIA, Carlos Alberto. Formação da culinária brasileira. São Paulo: Três Estrelas, 2014.

DURHAN, Eunice Ribeiro. A dinâmica da cultura. São Paulo: CosacNaify, 2004.

ETGES, Virgínia Elisabeta. A região no contexto da globalização: o caso do Vale do Rio Pardo. In: VOGHT, O. P.; SILVEIRA, R. L. L. da. Vale do Rio Pardo: (re)conhecendo a região. Santa Cruz do Sul: Edunisc, 2001.

Fundação de Economia e Estatística - FEE. Perfil Socioeconômico RS - Coredes. Vale do Rio Pardo. Disponível em: $<$ http://www.fee.rs.gov.br/perfilsocioeconomico/coredes/>. Acesso em: 30 mai. 2016. 
GIRARDI, Giovana. Por que o Rio Grande do Sul é a região com mais suicídios do país. Revista Galileu, São Paulo, n. 64, 2016.

HARVEY, David. Condição pós-moderna: uma pesquisa sobre as origens da mudança cultural. Tradução de Udail Ubirajara Sobral e Maria Stela Gonçalves. São Paulo: Edições Loyola, 2014.

HOBSBAWM, Eric J. Introdução: A invenção das tradições. In: HOBSBAWM, E. J.; RANGER, T. (Org.). A invenção das tradições. Tradução de Celina Cardim Cavalcante. 9. ed. São Paulo: Paz e Terra, 2014.

KARNOPP, Erica. Repensando o desenvolvimento rural no contexto territorial da agricultura familiar: estudos de caso. Redes, Santa Cruz do Sul, v. 19, ed. especial, p. 139-152, 2014.

KLARMANN, Herbert. Região e identidade regional: um estudo da espacialidade e representatividade regional no Vale do Rio Pardo. 1999. $189 \mathrm{f}$. Dissertação (Mestrado) - Curso de Desenvolvimento Regional, Universidade de Santa Cruz do Sul, Santa Cruz do Sul, 1999.

MAIA, Doralice Sátyro. A geografia e o estudo dos costumes e das tradições. Terra Livre, n. 16, p. 71-98, 2001.

MENEZES, Sônia de Souza Mendonça. Queijo de coalho: tradição cultural e estratégias de reprodução social na região nordeste. Revista de Geografia, v. 28, n. 1, p. 40-56, 2011.

MINAYO, Maria Cecília de Souza. O desafio do conhecimento: pesquisa qualitativa em saúde. São Paulo-Rio de Janeiro: Hucitec-Abrasco, 1992.

MIOR, Luiz Carlos. Agricultura familiar, agroindústria e desenvolvimento territorial. In: Colóquio Internacional de Desenvolvimento Rural
Sustentável. Florianópolis: 22 a 25 de agosto de 2007.

MORIN, Edgar. Cultura de massas no século XX: o espírito do tempo - Neurose. Tradução de Maura Ribeiro Sardinha. Rio de Janeiro: Forense Universitária, 1997.

OLIVEN, Ruben George. A parte e o todo: diversidade cultural no Brasil-Nação. Petrópolis: Vozes, 1992.

PLOEG, Jan Douwe Van Der. Camponeses e impérios alimentares: lutas por autonomia e sustentabilidade na era da globalização. Tradução de Rita Pereira. Porto Alegre: Editora da UFRGS, 2008.

POLLAN, Michael. Em defesa da comida: um manifesto. Tradução de Adalgisa Campos da Silva. Rio de Janeiro: Intrínseca, 2008.

POULAIN, Jean-Pierre. Sociologia da alimentação: os comedores e o espaço social alimentar. Tradução de Rossana Pacheco da Costa Proença, Carmen Sílvia Rial, Jaimir Conte. 2 ed. Florianópolis: Ed. da UFSC, 2013.

REINHARDT, Juliana Cristina. Dize-me o que comes e te direi quem és: alemães, comida e identidade. 2007. 229 f. Tese (Doutorado) Departamento de História, Setor de Ciências Humana, Letras e Artes, Universidade Federal do Paraná, Curitiba, 2007.

ROBERTS, Paul. O fim dos alimentos. Tradução de Ana Gibson. Rio de Janeiro: Elsevier, 2009.

SANTOS, Milton. Por uma outra globalização: do pensamento único à consciência universal. Rio de Janeiro: Record, 2000. 
SILVA, K. V.; SILVA, M. H. Dicionário de conceitos históricos. São Paulo: Contexto, 2009.

SILVEIRA, R. L. L. da; CAMPOS, H. A. Processos participativos em experiências recentes de planejamento regional: o caso do vale do Rio Pardo (RS). Redes, Santa Cruz do Sul, v. 17, n. 1, p. 203-216, jan-abr 2012.

WERLE, Flávia Obino Corrêa. Genealogia feminina: diálogo silencioso entre gerações. História da Educação, Porto Alegre, v. 18, n. 43, p. 127-143, mai./ago. 2014.

ZANETI, Tainá. Das panelas das nossas avós à alta gastronomia. Jundiaí: Paco Editorial, 2015. 